\title{
Tumor-related protein, the squamous cell carcinoma antigen binds to the intracellular protein carbonyl reductase
}

\author{
AKIHIRO MURAKAMI ${ }^{1}$, CHIKAKO FUKUSHIMA ${ }^{1}$, KEIKO YOSITOMI $^{1}$, \\ KOTARO SUEOKA ${ }^{1}$, SHUGO NAWATA ${ }^{1}$, MASANORI FUJIMOTO ${ }^{2}$, \\ KAZUYUKI NAKAMURA ${ }^{2}$ and NORIHIRO SUGINO ${ }^{1}$
}

\begin{abstract}
Departments of ${ }^{1}$ Obstetrics and Gynecology, and ${ }^{2}$ Biochemistry and Functional Proteomics, Yamaguchi University Graduate School of Medicine, 1-1-1 Minamikogushi, Ube 755-8505, Japan
\end{abstract}

Received December 15, 2009; Accepted February 8, 2010

DOI: 10.3892/ijo_00000624

\begin{abstract}
Squamous cell carcinoma antigen (SCCA) is a useful tumor marker for diagnosis and management of squamous cell carcinoma. Recent reports have shown that SCCA can influence the invasion or metastasis of cancer cells. However, it remained unclear how SCCA acts to mediate these biological functions. To solve this question, at first, SCCA1and SCCA2-glutathione S-transferase fusion protein were used to purify a protein which binds to SCCA1 or SCCA2, and the combined protein was identified by proteomic analysis. Secondly, immunocytochemical and immunohistochemical analyses were performed to investigate the localization of this protein. Third, Western blotting was performed to analyze the expression levels of this protein in keratinocytes and six kinds of uterine squamous cell carcinoma cell lines. Both SCCA1 and SCCA2 molecules bind to the cytoplasmic protein, which was identified to be carbonyl reductase $(\mathrm{CR})$. The immunostaining analyses revealed that $\mathrm{CR}$ is located in the cytoplasm of keratinocytes and the normal squamous epithelial cells of the uterine cervix as well as SCCA1 and SCCA2. The CR expression levels in six kinds of squamous cell carcinoma cell lines were lower compared to those in keratinocytes. In conclusion, CR binds to SCCA1 and SCCA2 and they are co-located in the same layer of the squamous epithelium, suggesting that CR may collaborate with SCCA1 and SCCA2 to mediate cancer behavior such as invasion or metastasis.
\end{abstract}

\section{Introduction}

Squamous cell carcinoma antigen (SCCA) was first discovered in the uterine cervical squamous cell carcinoma by Kato and

Correspondence to: Dr Akihiro Murakami, Department of Obstetrics and Gynecology, Yamaguchi University Graduate School of Medicine, 1-1-1 Minamikogushi, Ube 755-8505, Japan E-mail: muraaki@yamaguchi-u.ac.jp

Key words: SCC antigen, carbonyl reductase, cervical cancer
Torigoe (1), and was widely used as a useful tumor marker for squamous cell carcinoma of various organs (2-4). Recent molecular studies have revealed that SCCA is encoded by two highly homologous genes, SCCA1 and SCCA2, at 18q21.3 locus $(5,6)$. Interestingly, both SCCA1 and SCCA2 belong to the serine proteinase inhibitor (serpin) family $(5,7)$. SCCA1 inhibits both serine proteinase and cysteine proteinase, while SCCA2 inhibits serine proteinase, chymase and cathepsin G (8-11). These facts made us speculate that SCCAs may have important biological functions in squamous cell carcinoma. In fact, our previous studies have shown that both SCCA1 and SCCA2 showed some biological functions: SCCAs suppress the apoptotic cell death induced by natural killer cells, an antineoplastic agent, and irradiation $(12,13)$; SCCAs stimulate matrix metalloproteinase-9 production (14); suppressed SCCA2 promotes cancer cell invasion and migration in the decrease of E-cadherin expression (15). These results suggest the possibility that both SCCA1 and SCCA2 may be involved in the regulation of cancer cell behavior and the malignant potential. However, it was not fully understood what molecules bind to SCCAs or how SCCAs regulate such biological pathways and functions. Therefore, we investigated the molecules, which bind to SCCAs using molecular methods.

\section{Materials and methods}

Cell culture. The human uterine cervical SCC cell lines, BOKU, ME-180, SiHa, SKG I, SKG II and SKG IIIa, and the human normal keratinocyte cell line, PHK16-0b were used. SKG IIIa was kindly provided by Dr S. Nozawa (Keio University School of Medicine, Tokyo, Japan), and BOKU, SKG I, SKG II, ME-180 and keratinocyte PHK16-0b were purchased from Health Science Research Resources Bank (Osaka, Japan). BOKU, SKG I, SKG II and SKG IIIa were cultured in Ham's F 12 (Sigma, St. Louis, MO, USA) supplemented with $10 \%$ heat inactivated fetal calf serum, $100 \mathrm{U} / \mathrm{ml}$ penicillin, $100 \mu \mathrm{g} / \mathrm{ml}$ streptomycin. SiHa and ME180 were cultured in Eagle's minimal essential medium (Sigma), and PHK16-0b was cultured in defined keratinocyteSFM with growth supplement (Invitrogen, Carlsbad, CA, USA). These cell lines were cultured at $37^{\circ} \mathrm{C}$ in a humidified $5 \% \mathrm{CO}_{2}$ incubator. 
Binding of cellular proteins to GST fusion protein. A glutathione S-transferase (GST) fusion protein construct of $S C C A 1$, and SCCA2 cDNA were kindly provided by Gary A. Silverman (Harvard University, Boston, MA, USA). These fusion proteins are named GST-SCCA1 and GST-SCCA2, respectively. Their purification procedures were described previously (10). The in vitro binding study was performed as described previously (16). In brief, $1 \times 10^{8}$ of keratinocyte PHK16-0b was resuspended in the cell lysis buffer containing $20 \mathrm{mM}$ Tris- $\mathrm{HCl} \mathrm{pH} 8.0,1 \% \mathrm{NP}-40,2 \mathrm{mM}$ EDTA, and $60 \mathrm{mM} \mathrm{NaCl}$. Mild sonication was performed and unsolubilized materials were removed by centrifugation at $15,000 \mathrm{rpm}$ for $10 \mathrm{~min}$ at $4^{\circ} \mathrm{C}$. The cell lysate was mixed with glutathione sepharose 4B beads (GE Healthcare UK Ltd., Little Chalfont, UK) -GST fusion proteins (GST, GSTSCCA1, and GST-SCCA2) for $2 \mathrm{~h}$ at $4^{\circ} \mathrm{C}$ and then mixed with $100 \mu \mathrm{l}$ of a 1:1 slurry of glutathione sepharose 4B (GE Healthcare UK Ltd.). After incubation for $2 \mathrm{~h}$ at $4^{\circ} \mathrm{C}$, the beads were washed 8 times in the cell lysis buffer and the binding proteins were eluted with Laemmli's sample buffer for $10 \mathrm{~min}$ at $100^{\circ} \mathrm{C}$. The samples were fractionated by $10 \%$ SDS-PAGE and each protein was fixed and stained on the gel with $30 \%$ methanol, $10 \%$ acetic acid, and $0.1 \%$ Coomassie brilliant blue R-250 (CBB). The gel was destained with $30 \%$ methanol and $10 \%$ acetic acid until the stain of background was clear and colorless. The different protein bands between GST (the control), GST-SCCA1, and GST-SCCA2 were excised from the gels.

In-gel digestion and peptide mass fingerprinting. The CBB dye in the excised gels was removed by rinsing twice in $60 \%$ methanol, $50 \mathrm{mM}$ ammonium bicarbonate, $5 \mathrm{mM}$ DTT for $15 \mathrm{~min}$ and twice in $50 \%$ acetonitrile, $50 \mathrm{mM}$ ammonium bicarbonate, $5 \mathrm{mM}$ DTT for $7 \mathrm{~min}$. The gel piece was dehydrated in $100 \%$ acetonitrile and then rehydrated with an in-gel digestion reagent containing $10 \mu \mathrm{g} / \mathrm{ml}$ sequencing grade trypsin (Promega, Madison, WI, USA) in 30\% acetnitrile, $50 \mathrm{mM}$ ammonium bicarbonate, $5 \mathrm{mM}$ DTT. The in-gel digestion was performed overnight at $30^{\circ} \mathrm{C}$. After the in-gel digestion, $1 \mu \mathrm{l}$ of the reaction mixture was removed and $1 \mu \mathrm{l}$ of the matrix solution $(10 \mathrm{mg} / \mathrm{ml} \alpha$-cyano-4-hydroxycinnamic acid in $50 \%$ acetonitrile, $40 \%$ methanol, $0.1 \%$ TFA) was added on a MALDI target plate. MALDI-TOF MS for peptide mass fingerprinting was performed on a Shimadzu Biotech AXIMA-CFR mass spectrometer (Kyoto, Japan) in reflection mode. The MS-Fit database search engine of the Protein Prospector web site was used for protein identification.

Preparation of anti-SCCA binding protein polyclonal antibody. The peptide, sequence CHQKEGWPSSAYG, was synthesized and conjugated to keyhole limpet hemocyanin, via the aminoterminal cystein of the synthetic peptide, which is not present in the deduced amino acid sequence. New Zealand white rabbits were injected three times with the antigen. In order to assess the effectiveness of the immunization, an enzymelinked immunosorbent assay with free peptide-coated microtiter plates was performed to measure the antibody titer. The rabbits were bled 10 days after the last injection and antiserum was collected and stored at $4{ }^{\circ} \mathrm{C}$. All animal experiments were carried out in accordance with the institutional guidelines.
Immunoprecipitation and Western blot analysis. Cultured $1 \times 10^{8}$ of keratinocytes were resuspended in $1 \mathrm{ml}$ of lysis buffer (50 mM Tris, $0.1 \%$ SDS, $0.5 \%$ Na Deoxycholate, $150 \mathrm{mM}$ $\mathrm{NaCl}$ and $1 \%$ Triton $\mathrm{X}-100$ ), mild sonication was performed, and unsolubilized materials were removed by centrifugation at $15,000 \mathrm{rpm}$ for $10 \mathrm{~min}$ at $4^{\circ} \mathrm{C}$. The cell lysate was mixed with $60 \mu \mathrm{l}$ of a $50 \%$ of protein A-sepharose beads (Kirkegaard and Perry Laboratories, Gaithersburg MD, USA) for $1 \mathrm{~h}$ at $4^{\circ} \mathrm{C}$. After centrifugation at $14,000 \mathrm{x} \mathrm{g}$, the supernatant was incubated with anti-carbonyl reductase (CR) rabbit serum or normal rabbit serum as the negative control. The antigenantibody complexes were precipitated by incubating for $3 \mathrm{~h}$ at $4^{\circ} \mathrm{C}$ with $60 \mu \mathrm{l}$ of $50 \%$ of immobilized protein A-sepharose beads. The beads were boiled in $50 \mu 1$ of Laemmli's sample buffer for $2 \mathrm{~min}$. The eluted proteins were analyzed by $10 \%$ of SDS-polyacrylamide gel. After SDS-PAGE was completed, proteins were transferred to the polyvinylidene difluoride membrane (ATTO, Tokyo, Japan) with semi-dry type blotting system. The transferred membranes were stained by immunochemical technique consisted of following procedure: after blocking the membrane with the blocking solution $(5 \%$ skimmed milk with $0.1 \%$ Tween-20 dissolved in Tris-buffered saline, $\mathrm{pH} 7.5)$, the blotted membrane was incubated with the anti-SCCA monoclonal antibody, Mab 13, as the first antibody, which was diluted in the blocking solution. Then, the membrane was incubated with the peroxidase conjugated second antibody diluted in the blocking solution. Finally, ECL-Western blotting detection system (GE Healthcare UK Ltd.) was applied according to the manufacturer's protocol and then the membranes were exposed to the hyperfilm-ECL (GE Healthcare UK Ltd.).

Immunocytochemistry and immunohistochemistry. The reactivity to the cultured keratinocyte PHK16-0b and human normal squamous epithelium from uterine cervix was assessed by immunostaining technique. Keratinocytes PHK16-0b were cultured on the chamber slides (BD Falcon, Franklin Lakes, USA), were fixed with $4 \%$ paraformaldehyde for $1 \mathrm{~h}$ at room temperature and washed with PBS and the human specimens were fixed in $10 \%$ buffered formalin and embedded in paraffin. All paraffin blocks were cut into $3 \mu \mathrm{m}$-thick sections and the sections were de-paraffinized in xylenes and rehydrated in ethanol, the samples were washed with cold PBS. The streptavidin-biotin-peroxidase complex technique was used for immunostaining as follows: endogeneous peroxidase was blocked by incubating in $0.5 \%$ hydrogen peroxide in methanol for $50 \mathrm{~min}$ at room temperature, then, the cells were washed three times with cold PBS. After incubation with $10 \%$ normal rabbit serum (SCCA) or $10 \%$ normal goat serum (CR) to block nonspecific binding, the specimens were sequentially incubated with the primary antibody against SCCA1 and SCCA2 (both were kindly provided by Gary A. Silverman) or anti-CR rabbit serum at $4^{\circ} \mathrm{C}$ overnight. After the incubation, they were rinsed in cold PBS and incubated for $30 \mathrm{~min}$ at room temperature with biotinylated anti-mouse $\operatorname{IgG}+\operatorname{IgA}+\operatorname{IgM}$ (SCCA) or anti-rabbit $\operatorname{IgG}+\operatorname{Ig} A+\operatorname{IgM}(\mathrm{CR})$ using with HISTFINE SAB-PO kit (Nichirei, Tokyo, Japan) followed by streptavidin-biotin-peroxidase complex. The reaction was revealed by adding diaminobenzidinetetrahydrocholoride 


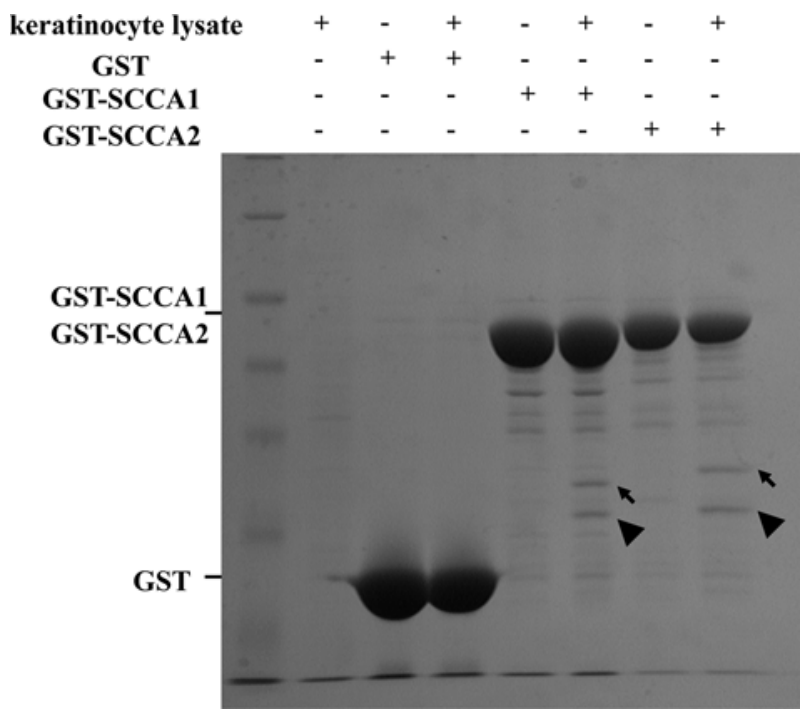

Figure 1. Detection of proteins on the SDS-polyacrylamide gel. The lysate from keratinocytes was mixed with GST, GST-SCCA1, and GST-SCCA2 proteins, and coupled with glutathione sepharose beads. Beads were washed, resuspended in Laemmli's sample buffer, and subjected to SDS-PAGE. Then the gel was stained with Coomassie brilliant blue R-250. The arrows indicate the SCCA molecule and the arrowheads indicate the carbonyl reductase (CR) molecule. The positions of GST, GST-SCCA1, and GST-SCCA2 are indicated on the left. SCCA and CR molecules were specifically recovered by glutathione sepharose beads when GST-SCCA1 and GST-SCCA2 were mixed with keratinocyte cell lysate.

chromogen mixture (Sigma). After hematoxylin couterstaining, slides were permanently mounted and analyzed for the presence and distribution of the immunostaining.

SDS-PAGE and Western blot analysis. Cultured keratinocytes and six kinds of squamous cell carcinoma cell lines were resuspended in Laemmli's sample buffer and mild sonication was performed. These samples were boiled for $10 \mathrm{~min}$ and unsolubilized materials were removed by centrifugation at $15,000 \mathrm{rpm}$ for $10 \mathrm{~min}$ at $4^{\circ} \mathrm{C}$. Total proteins $(150 \mu \mathrm{g})$ were electrophoresed on $10 \%$ SDS-polyacrylamide gels. The transfer and blocking procedures were described above. After the blocking procedure, the blotted membrane was incubated with the anti-carbonyl reductase rabbit serum, as the first antibody, which was diluted in the blocking solution. Then, the membrane was incubated with the peroxidase conjugated anti-rabbit goat antibody diluted in the blocking solution. Finally, ECL-Western blotting detection system (GE Healthcare UK Ltd.) was applied according to the manufacturer's protocol and then the membranes were exposed to the hyperfilm-ECL (GE Healthcare UK Ltd.).

\section{Results}

Detection of proteins on SDS-polyacrylamide gels. To investigate the possibility of protein-protein interactions of SCCA1 or SCCA2 molecules with the intracellular proteins, affinity purification was carried out using GST-SCCA1 or GSTSCCA2, respectively. The cell lysate was incubated with GST-SCCA1 and GST-SCCA2 and combined proteins were recovered by glutathione agarose. Protein bands were

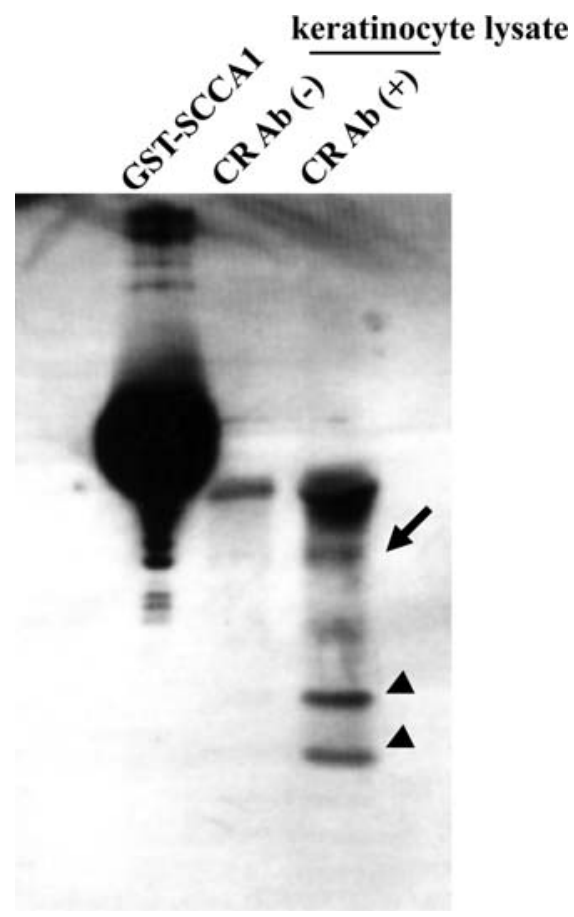

Figure 2. Immunoprecipitation of keratinocytes with anti-CR rabbit serum or normal rabbit serum as the negative control followed by Western blot analysis with anti-SCCA monoclonal antibody. The fusion protein GSTSCCA1 is the positive control for Western blot analysis. The arrow indicates the full length of SCCA and the arrowheads indicate the degraded products of SCCA.

visualized on the SDS-polyacrylamide gels after CBB staining (Fig. 1). The two bands were identified by peptide mass fingerprinting. Each band provided good amino acid sequences with LC-MS/MS. These proteins were identified as SCCA and $\mathrm{CR}$.

Immunoprecipitation and Western blot analysis. To confirm that SCCA binds to CR, immunoprecipitation followed by Western blotting using anti-SCCA monoclonal antibody was carried out. The major band with molecular weights of $45 \mathrm{kDa}$ was revealed the full length of SCCA. Small molecular weights of $30 \mathrm{kDa}$ and $15 \mathrm{kDa}$ were confirmed the degraded products of SCCA (Fig. 2). This result suggests that SCCA binds to $\mathrm{CR}$.

Immunocytochemistry and immnohistochemistry. CR was located in the cytoplasm as well as SCCA1 and SCCA2 (Fig. 3). Immunohistochemistry revealed that SCCA1 and SCCA2 were located in the cytoplasm of the normal squamous epithelial layer (Fig. 4). CR was similarly located in the same normal squamous epithelial layer (Fig. 4).

Western blot analysis for CR expression in the cultured cell lines. To investigate the expression levels of CR in keratinocytes and six kinds of squamous cell carcinoma cell lines, Western blot analysis was carried out using anti-CR rabbit serum. Western blot analysis showed that CR expression in six kinds of squamous cell carcinoma cell lines are lower compared to that in keratinocytes (Fig. 5). 

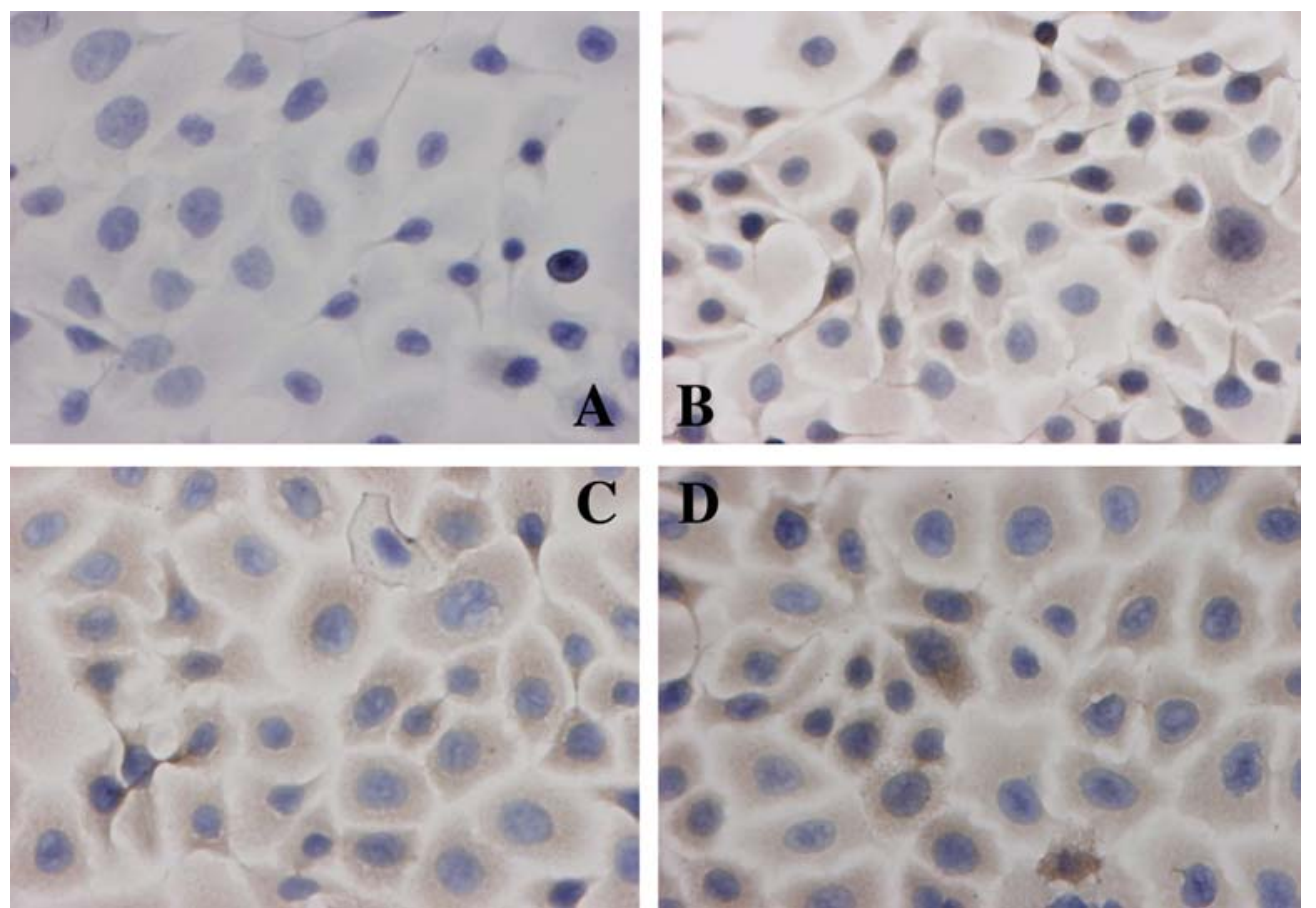

Figure 3. Localization of CR, SCCA1, and SCCA2 in keratinocytes. Immunocytochemical staining of CR, SCCA1, and SCCA2 were performed in cultured keratinocytes. Original magnification x100 (A) negative control (B) CR (C) SCCA1 (D) SCCA2.

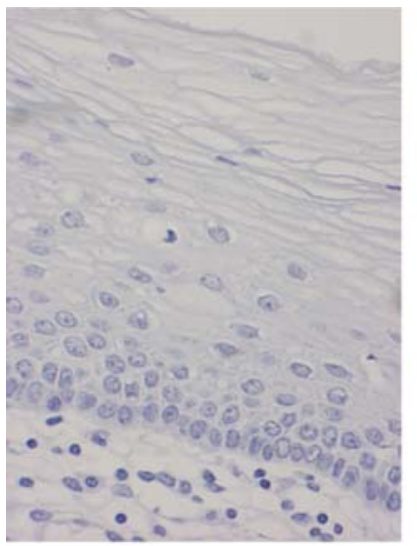

A

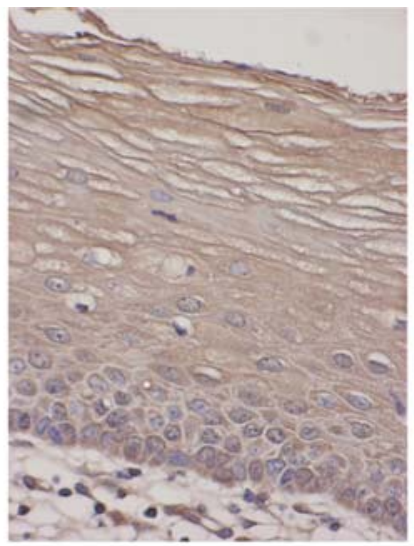

B

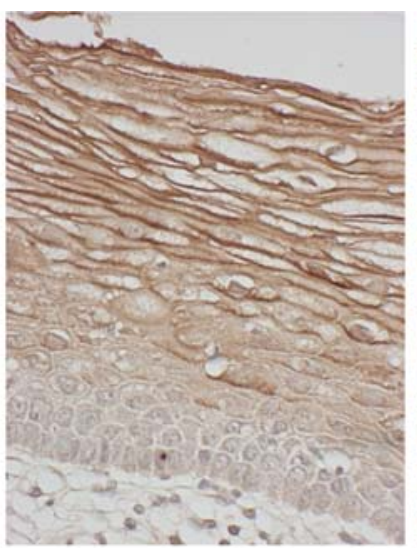

C

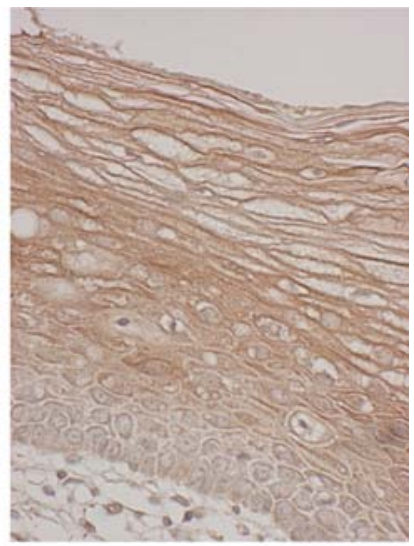

D

Figure 4. Localization of CR, SCCA1, and SCCA2 in the normal squamous epithelial layer. Immunohistochemical staining of CR, SCCA1, and SCCA2 in normal squamous epithelium. Original magnification x100 (A) negative control (B) CR (C) SCCA1 (D) SCCA2.

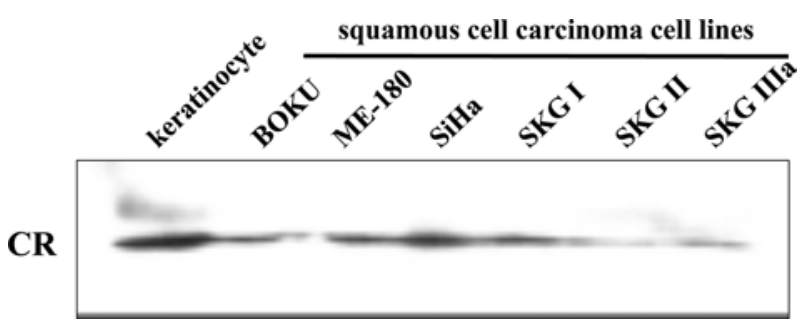

Figure 5. CR expression in human keratinocyte and six kinds of uterine cervical squamous cell carcinoma cell lines. CR expression was analyzed by Western blotting in human keratinocytes and the cell lines BOKU, ME-180, SiHa, SKG I, SKG II, SKG IIIa.

\section{Discussion}

The present study showed that there is a protein in the cytosol that both SCCA1 and SCCA2 are binding in normal keratinocytes, and that the protein was identified as CR. CR is a NADPH-dependent, mostly monometric, cytosolic enzyme with broad substrate specificity for carbonyl compounds $(17,18)$. It has been therefore extensively studied in relation to its ability to reduce a variety of carbonyl conpounds; the antitumor anthracycline antibiotics, daunorubicin (19) and doxorubicin, and prostaglandins (20). Prostaglandins, especially prostaglandin E2 (PGE2), play 
important roles in modulating tumor growth and metastasis in many kinds of human tumors. PGE2 promotes development and progression of cancer cells (21), by promoting angiogenesis through enhancement of vascular endothelial growth factor expression $(22,23)$, inhibition of apoptosis (24), and regulation of cytokines (25). Therefore, it is speculated that CR may play important roles in suppression of tumor growth and metastasis by inactivation of PGE2. It was recently reported that $\mathrm{CR}$ suppresses tumor growth and metastatic behavior (26). However, the mechanisms by which $\mathrm{CR}$ acts in cancer cell proliferation and malignant behavior is not fully understood.

Our previous study showed that suppression of SCCA2 expression promoted cell invasion and cell migration with decreased expression of E-cadherin, and that blockage of Ecadherin function by anti E-cadherin antibody treatment inhibited cell invasion and cell migration (15). Our recent study also showed that there was a significant relationship in expression patterns between SCCA2 and E-cadherin in squamous cell carcinoma tissues (27). Furthermore, decreased SCCA2 expression, as well as decreased Ecadherin expression, was closely associated with high incidence of lymph node metastasis (27). These findings strongly suggest that SCCA regulates cancer cell behaviors through alternation in E-cadherin expression. Interestingly, recent report showed that the cultured cancer cells with decreased CR expression showed high incidence of metastasis (26). Our present study shows that SCCAs and CR co-located in the cytoplasm in the normal squamous epithelial layer. Furthermore, CR expression levels of six kinds of squamous cell carcinoma cell lines were lower compared to that in keratinocytes. These findings strongly suggest a possibility that CR may collaborate with SCCA1 and SCCA2 to mediate malignant behavior such as invasion or metastasis by controlling E-cadherin expression. This hypothesis also leads us to think that SCCAs and CR may be key molecules concerned with epithelial mesenchymal transition. However, it is unclear how CR modifies the function of SCCAs and further investigation is needed regarding the mechanisms by which CR modulates malignant behavior.

The present study may provide new insight into understanding the mechanism for malignant behavior of cancer cells. It may be possible to control cancer cell invasion and metastasis by molecular targeting therapy with control of CR and SCCA in near future.

\section{Acknowledgements}

We thank Dr Gary A. Silverman (Harvard University, Boston, MA, USA) for the specific antibodies for SCCA1 and SCCA2 and GST fusion protein construct of SCCA1 and $S C C A 2$ cDNA. This work was supported by Grant-in-Aid for Scientific Research on Priority Areas (C-2) from the Ministry of Education, Science, Sports and Culture (20591950, 20591949), Japan.

\section{References}

1. Kato $\mathrm{H}$ and Torigoe $\mathrm{T}$ : Radioimmunoassay for tumour antigen of human cervical squamous cell carcinoma. Cancer 40: $1621-1628,1977$.
2. Kato H, Tamai K, Morioka H, Nagai M, Nagaya $T$ and Torigoe T: Prognostic significance of the tumour antigen TA-4 in squamous cell carcinoma of the uterine cervix. Am J Obstet Gynecol 145: 350-354, 1983.

3. Maruo T, Shibata K, Kimura A, Hoshina A and Mochizuki M: Tumour-associated antigen, TA-4, in the monitoring of the effects of therapy for squamous cell carcinoma of the uterine cervix. Cancer 59: 302-308, 1985.

4. Brioschi PA, Bischof P, Delafosse C and Krauer F: Squamous cell carcinoma antigen (SCC-A) values related to clinical outcome of pre-invasive and invasive cervical carcinoma. Int J Cancer 47: 376-379, 1991

5. Schneider SS, Schick C, Fish KE, Miller E, Pena JC, Treter SD, Hui SM and Silverman GA: A serine proteinase inhibitor locus at $18 \mathrm{q} 21.3$ contains a tandem duplication of the human squamous cell carcinoma antigen gene. Proc Natl Acad Sci USA 92: 3147-3151, 1995.

6. Kuwano A, Kondo I, Kishi F, Suminami Y and Kato H: Assignment of the squamous cell carcinoma antigen locus (SCC) to $18 \mathrm{q} 21$ by in situ hybridization. Genomics 30: 626, 1995.

7. Suminami Y, Kishi F, Sekiguchi K and Kato H: Squamous cell carcinoma antigen is a new member of the serine protease inhibitors. Biochem Biophys Res Commun 181: 51-58, 1991.

8. Nawata S, Tsunaga N, Numa F, Tanaka T, Nakamura K and Kato $\mathrm{H}$ : Serine protease inhibitor activity of recombinant squamous cell carcinoma antigen towards chymotrypsin, as demonstrated by sodium dodecyl sulfate-polyacrylamide gel electrophoresis. Electrophoresis 16: 1027-1030, 1995.

9. Nawata S, Nakamura K, Tanaka T, Numa F, Suminami Y, Tsunaga N, Kakegawa H, Katsunuma N and Kato H: Electrophoretic analysis of the 'cross-class' interaction between novel inhibitory serpin, squamous cell carcinoma antigen-1 and cystein proteinases. Electrophoresis 18: 784-789, 1997.

10. Schick C, Kamachi Y, Bartuski A J, Çataltepe S, Schechter NM, Pemberton PA and Silverman GA: Squamous cell carcinoma antigen 2 is a novel serpin that inhibits the chymotrypsin-like proteinases cathepsin $\mathrm{G}$ and mast cell chymase. J Biol Chem 17: $1849-1855,1997$.

11. Schick C, Pemberton PA, Shi GP, Kamachi Y, Çataltepe S, Bartuski AJ, Cornstein ER, Brömme D, Chapman HA and Silverman GA: Cross-class inhibition of the cysteine proteinases cathepsin K, L, S by the serpin squamous cell carcinoma antigen 1: a kinetic analysis. Biochemistry 37: 5258-5266, 1998.

12. Suminami Y, Nagashima S, Vujanovic NL, Hirabayashi K, Kato $\mathrm{H}$ and Whiteside TL: Inhibition of apoptosis in human tumour cells by the tumour-associated serpin, SCC antigen-1. Br J Cancer 82: 981-989, 2000.

13. Murakami A, Suminami Y, Hirakawa H, Nawata S, Numa F and Kato H: Squamous cell carcinoma antigen suppresses radiation-induced cell death. Br J Cancer 84: 851-858, 2001.

14. Sueoka K, Nawata S, Nakagawa T, Murakami A, Takeda O, Suminami Y, Kato $\mathrm{H}$ and Sugino N: Tumor-associated serpin, squamous cell carcinoma antigen stimulates matrix metalloproteinase- 9 production in cervical squamous cell carcinoma cell lines. Int J Oncol 27: 1345-1353, 2005.

15. Murakami A, Nakagawa T, Kaneko M, Nawata S, Takeda O, Kato $\mathrm{H}$ and Sugino N: Suppression of SCC antigen promotes cancer cell invasion and migration through the decrease in Ecadherin expression. Int J Oncol 29: 1231-1235, 2006.

16. Kishi F, Yoshida T and Aiso S: Location of NRAMP1 on the plasma membrane and its association with microtubules. Mol Immun 33: 1241-1246, 1996.

17. Wermuth B, Mader-Heinemann G and Ernst E: Cloning and expression of carbonyl reductase from rat testis. Eur J Biochem 228: 473-479, 1995 .

18. Jez JM, Bennett MJ, Schlegel BP, Lewis M and Pennning TM: Comparative anatomy of the aldo-keto reductase superfamily. Biochem J 326: 625-636, 1997.

19. Ahmed NK, Felsted RI and Bachur NR: Heterogeneity of anthracycline antibodies carbonyl reductases in mammalian livers. Biochem Pharmacol 27: 2713-2719, 1978.

20. Lee SC and Levine L: Prostaglandin metabolism I. Cytoplasmic reduced nicotinamide adenine dinucleotide phosphate-dependent and microsomal reduced nicotinamide adenine dinucleotidedependent prostaglandin E9-ketoreductase activities in monkey and pigeon tissues. J Biol Chem 249: 1369-1375, 1974.

21. Sheng H, Shao J, Washington MK and DuBois RN: Prostaglandin E2 increases growth and mobility of colorectal carcinoma cells. J Biol Chem 276: 18075-18081, 2001. 
22. Tsujii M, Kawano S, Tsuji S, Sawano H, Hori M and DuBois RN Cyclooxygenase regulates angiogenesis induced by colon cancer cells. Cell 93: 705-716, 1998.

23. Cianchi F, Cortesini C, Bechi P, Fantappie O, Messerini L, Vannacci A, Sardi I, Baroni G, Boddi V, Mazzanti R and Masini E: Up-regulation of cyclooxygenase 2 gene expression correlates with tumor angiogenesis in human colorectal cancer. Gastroenterology 121: 1339-1347, 2001.

24. Sheng H, Shaw J, Morrow JD, Beauchamp RD and DuBois RN: Modulation of apoptosis and Bcl-2 expression by prostaglandin E2 in human colon cancer cells. Cancer Res 58: 362-366, 1998.

25. Huang M, Stolian M, Sharma S, Mao JT, Zhu L, Miller PW, Wollman J, Herschman H and Dubinett SM: Non-small cell lung cancer cyclooxygenase-2 dependent regulation of cytokine balance in lymphocytes and macrophages: up-regulationof interleukin 10 and down-regulation of interleukin 12 production. Cancer Res 58: 1208-1216, 1998.
26. Ismail E, Al-Mulla F, Tsuchida S, Suto K, Motley P, Harrison PR and Birnie GD: Carbonyl reductase: a novel metastasismodulating function. Cancer Res 60: 1173-1176, 2000.

27. Murakami A, Nakagawa T, Fukushima C, Torii M, Sueoka K, Nawata S, Takeda O, Ishikawa $\mathrm{H}$ and Sugino N: Relationship between decreased expression of squamous cell carcinoma antigen 2 and E-cadherin in primary cervical cancer lesions and lymph node metastasis. Oncol Rep 19: 99-104, 2008. 